\title{
CITRAAN DALAM KUMPULAN PUISI DONGENG-DONGENG YANG TAK UTUH KARYA BOY CANDRA DAN IMPLIKASINYA
}

\author{
Mela Suciati, Tri Mulyono, Khusnul Khotimah \\ Universitas Pancasakti Tegal \\ melasuciati09@gmail.com,upstrimulyono@gmail.com,khusnulkups@gmail.com
}

\begin{abstract}
ABSTRAK
Penelitian ini mengkaji citraan dalam puisi. Tujuan penelitian ini adalah mendeskripsikan citraan dalam kumpulan puisi Dongeng-Dongeng yang tak Utuh karya Boy Candra dan mendeskripsikan implikasi hasil penelitian terhadap pembelajaran bahasa Indonesia di SMP. Pendekatan yang digunakan dalam penelitian ini yaitu pendekatan objektif. Sumber data dalam penelitian ini yaitu puisi Dongeng-Dongeng yang tak Utuh karya Boy Candra yang diterbitkan pada tahun 2019. Wujud data dalam penelitian ini berupa baris yang menunjukan adanya aspek citraan dalam kumpulan puisi Dongeng-Dongeng yang tak Utuh karya Boy Candra. Teknik pengumpulan data yang digunakan dalam penelitian ini adalah teknik baca dan catat. Teknik analisis data menggunakan metode deskriptif analisis. Teknik penyajian hasil analisis data yang digunakan adalah metode informal. Berdasarkan hasil penelitian terdapat enam jenis citraan dalam kumpulan puisi Dongeng-Dongeng yang tak Utuh yaitu (1). Citraan penglihatan berjumlah 58 data:46,4\%. (2). Citraan pendengaran berjumlah 21 data:16,8\%. (3). Citraan penciuman berjumlah 4 data:3,2\%. (4). Citraan rasaan berjumlah 5 data:4\%. (5). Citraan rabaan berjumlah 27 data:21,6\%. (6). Citraan gerak berjumlah 10 data:8\%. Citraan yang paling dominan digunakan dalam kumpulan puisi Dongeng-Dongeng yang tak Utuh kary Boy Candra adalah citraan penglihatan yang berjumlah 58 data:46,4\%. Hasil penelitian ini diimplikasikan pada pembelajaran bahasa Indonesia di SMP kelas VIII.
\end{abstract}

Kata Kunci: Puisi, citraan, Implikasi Pembelajaran

\begin{abstract}
This study examines images in poetry. The purpose of this study is to describe the image in a collection of poems of Intact Tales by Boy Candra and describe the implications of the results of research on learning Indonesian in junior high school. The approach used in this research is an objective approach. The data source in this research is Boy Candra's Whole Poems written by Boy Candra published in 2019. The form of data in this study is in the form of lines that show the image aspect in the collection of Whole Tales of Whole Poems written by Boy Candra. Data collection techniques used in this study are reading and note taking techniques. Data analysis techniques using descriptive analysis method. The technique of presenting the results of data analysis used is the informal method. Based on the results of the study there are six types of images in the collection of Intact Tales of Poems namely (1). Vision images totaled 58 data: 46.4\%. (2). Hearing imagery totaling 21 data: 16.8\%. (3). The olfactory image amounted to 4 data: 3.2\%. (4). Feelings images totaled 5 data: 4\%. (5). Palpation imagery totaling 27 data: 21.6\%. (6). Motion imagery totaling 10 data: 8\%. The most dominant imagery used in a collection of Unclean Tales by Boy Candra is visual imagery, amounting to 58 data: $46.4 \%$. The results of this study are implicated in learning Indonesian in junior high school.
\end{abstract}

Keywords: Poems, images, learning implications 


\section{PENDAHULUAN}

Karya sastra merupakan karya imajinatif, fiktif, dan ungkapan ekspresif penyair (Susanto dalam Sujoko, dan Edy, 2020:112). Karya sastra merupakan karya seni yang mengandung nilai intrinsik yang dapat dijadikan pedoman bagi kehidupan manusia. Karya sastra adalah tulisan atau karangan yang mengandung nilai-nilai kebaikan yang ditulis menggunakan bahasa yang indah (Kosasih dalam Sujoko, dan Edy, 2020:112)

Dalam karya sastra, bahasa merupakan medium utama penyampaian gagasan penyair. Melalui bahasa, penyair menggungkapkan pengalaman dan menyajikannya dalam model tertentu, apakah dalam model drama, novel, cerita pendek atau puisi (Siswantoro, 2010:33-34). Pemakaian bahasa di dalam puisi berbeda dengan pemakaian bahasa biasa yang cenderung menggunakan makna sebenarnya atau belum dipoles, tetapi bahasa didalam puisi memiliki kekhususannya yang tunduk terhadap norma dan kaidah puisi. Bahasa puisi ditata menurut konvensinya sehingga di dalamnya terdapat majas seperti metafora, sinekdoke, hiperbola, similie, aliterasi, konsonan, sajak, ritme, pencitraan dan sebagainya sehingga bahasanya tidak lagi alamiah (Siswantoro, 2010:35). Dalam mengkaji sebuah karya sastra unsur bahasa merupakan unsur yang sangat penting.

Berdasarkan ragamnya karya sastra dibedakan atas prosa, puisi, dan drama. Penelitian ini tidak membahas ketiga bentuk karya sastra tersebut. Penulis hanya memilih salah satu yaitu puisi sebagai masalah yang akan diteliti.

Dunton (dalam Pradopo, 2012:6) berpendapat bahwa puisi merupakan gagasan penyair secara konkret dan artistik dalam bahasa penuh emosi dan berirama. Di sini, contohnya melalui perumpamaan, melalui citra-citra, serta disusun secara indah (misalnya selaras, simetris, penentuan katanya cermat, dan sebagainya) dan bahasanya penuh perasaan, serta berirama bagaikan musik (perubahan bunyi kata-katanya berurutan dengan baik).

Pradopo (2012:79) mengungkapkan bahwa dalam puisi, penyair memanfaatkan gambaran-gambaran angan dalam sajaknya untuk memberikan gambaran lebih nyata kepada pembaca, menimbulkan suasana khusus serta untuk memikat minat pembaca. Gambaran-gambaran angan ini disebut citraan (imagery) yang digunakan oleh penulis dalam puisi disamping alat kepuitisan lainnya. Altenbernd (dalam pradopo, 2012:79-80) Citraan merupakan gambaran-gambaran dalam pikiran serta bahasa dalam menggambarkannya. Gambaran pikiran dihasilkan akibat penafsiran kita terhadap objek yang bisa ditangkap oleh mata, saraf penglihatan, dan daerah-daerah otak yang berkaitan serta menghasilkan sebuah efek yang menyerupai gambaran dalam pikiran.

Coombes (dalam Pradopo, 2012:80) berpendapat dalam tangan seorang penyair yang bagus, imaji itu nyata dan hidup, berada dalam puncak keindahannya untuk mengoptimalkan, menjernihkan, memperkaya; imaji yang dapat membuat pembaca merasakan pengalaman penyair terhadap objek serta suasana yang 
dialami penyair, memberi gambaran yang setepatnya, kuat, hidup, cermat, serta dekat dengan hidup kita.

Boy Candra merupakan sastrawan yang aktif menulis. Salah satunya yaitu puisi Dongeng-Dongeng yang tak Utuh. Peranan bahasa dalam puisi sangatlah penting, khususnya sarana bahasa yang berkaitan dengan citraan. Peneliti tertarik untuk menganalisis unsur puisi. Namun, dalam penelitian ini unsur yang akan diteliti merupakan unsur yang berupa citraan dalam kumpulan puisi DongengDongeng yang tak Utuh karya Boy Candra.

Tujuan penelitian ini adalah untuk mendeskripsikan citraan dalam kumpulan puisi Dongeng-Dongeng yang tak Utuh karya Boy Candra dan mendeskripsikan implikasi hasil penelitian terhadap pembelajaran bahasa Indonesia di SMP.

\section{LANDASAN TEORI}

Pengertian puisi menurut Parrine (dalam Siswantoro, 2010:23) puisi merupakan semacam bahasa yang mengungkapkan lebih padat dan lebih mendalam dari bahasa harian. Pradopo (2012:13) puisi ialah karya seni yang puitis. Dikatakan puitis bilamana mampu membangkitkan perasaan, menimbulkan respons yang jelas, dan menarik perhatian. Secara umum apabila dalam sajak mebangkitkan keharuan dikatakan puitis. Kepuitisan dapat dilakukan dengan berbagai upaya, contohnya dengan bentuk visual: tipografi, susunan bait; dengan bunyi: lambang rasa, aliterasi, asonansi, persajakan, serta orkestrasi; pemilihan kata (diksi), perumpamaan, dan sebagainya. Puisi yakni seni tertulis dimana bahasa digunakan untuk kualitas keindahannya untuk tambahan, atau selain makna semantiknya (Sadikin dalam Rahimah, 2017:94).

Waluyo (dalam Laila, 2016:13) mengungkapan puisi ialah bentuk karya sastra yang menyatakan pikiran dan perasaan penyair secara imajinatif dan disusun dengan memusatkan semua kekuatan bahasa dengan struktur fisik dan struktur batin. Menurut Waluyo (dalam Mabruri, dan Sri, 2015:137) mengemukakan bahwa puisi terdiri atas dua unsur pokok yaitu struktur fisik dan struktur batin. Kedua bagian itu terdiri dari unsur-unsur yang saling mengikat keterjalinan dan semua unsur tersebut membentuk totalitas makna yang utuh. Struktur fisik terdiri atas diksi, pengimajian, kata konkret, majas, rima, ritma, metrum, dan tipografi. Struktur batin puisi terdiri atas tema, perasaan, nada, dan amanat.

Pada hakikatnya, permasalahan citraan masih berhubungan dengan persoalan diksi, yang maksudnya pemilihan terhadap kata tertentu dapat menimbulkan daya saran yang menyebabkan imajinasi pembaca terhadap sesuatu hal. Melalui daya bayang yang dimiliki oleh pembaca, imajinasi pembaca tersentuh sebab sebagian dari indra dipancing untuk membayangkan sesuatu. Daya bayang atau imajinasi tergantung kepada kemampuan pembaca (Hasanuddin WS, 2002:110). Citraan merupakan penggunaan bahasa yang dapat membangkitkan kesan yang konkret terhadap suatu objek, aksi, pemandangan, tindakan, atau pernyataan yang mampu 
membedakannya dengan pernyataan yang abstrak (Baldic dalam Yono, dan Mimi, 2017:201)

Citraan merupakan pemanfaatan sarana kebahasaan didalam puisi. Penggunaan citraan secara baik dan tepat dapat menimbulkan kepuitisan (Hasanuddin WS, 2002:111). Nurizzati (dalam Maulina, 2016:179) menjelaskan tentang fungsi citraan ialah untuk mempermudah pembaca dalam memahami puisi serta memperoleh gambaran yang jelas, menyebabkan gambaran lebih hidup dalam pikiaran serta pengindraan, dan memikat perhatian.

Menurut Hasanuddin WS (2002:117-129) jenis-jenis citraan yakni, (1) Citraan penglihatan merupakan citraan yang memberi dorongan kepada indra penglihatan untuk memberi gambaran terhadap sesuatu yang tidak terlihat seakan-akan dapat terlihat, (2) Citraan pendengaran ialah citraan yang ditimbulkan akibat indra pendengaran. Ide-ide yang ditulis penyair terasa hadir dan membangkitkan suatu suasana dalam diri pembaca. misalnya, bunyi lonceng, auman harumau, seru serigala dan sebagainya, (3) Citraan penciuman ialah ide-ide abstrak coba dikonkretkan oleh penyair dengan cara digambarkan menggunakan rangsangan yang seakan-akan dapat ditangkap oleh indra penciuman, (4) Citraan rasaan ialah penyair menggambarkan sajaknya lewat pemilihan kata untuk membangkitkan emosi pembaca. Pemilihan kata tersebut untuk membawa imajinasi pembaca terhadap sesuatu yang seakan-akan dapat dirasakan oleh indra pencecapan pembaca, (5) Citraan rabaan ialah citraan yang ditimbulkan akibat aktivitas indra kulitnya yang seakan-akan dapat tersentuh atau bersentuhan. Sesuatu yang diungkapkan penyair dalam sajaknya seakan-akan dapat dirasakan oleh pembaca, misalnya kata lengannya tersayat pisau atau perihnya hati bagai tertusuk sembilu, dan (6) Citraan gerak ialah citraan yang menggambarkan sesuatu yang diam seakanakan dapat bergerak. Citraan gerak dimanfaatkan untuk lebih menghidupkan gambaran dalam sajak.

\section{METODE PENELITIAN}

Pendekatan yang digunakan dalam penelitian ini yaitu pendekatan objektif. Pendekatan objektif yakni pendekatan yang memusatkan pemahamannya terhadap unsur intrinsik (Ratna, 2010:73).

Sumber data dalam penelitian ini ialah data primer dan data sekunder. Data primer yang digunakan yaitu kumpulan puisi Dongeng-Dongeng yang Tak Utuh karya Boy Candra dan sumber data sekunder ialah berbagi acuan yang selaras dengan objek dan tujuan penelitian. Data sekunder meliputi: jurnal, teori-teori sastra, hasil penelitian ilmiah dan sumber lain yang berkaitan erat dengan data primer. Teknik pengumpulan data dalam penelitian ini menggunakan teknik baca dan catat.

Teknik analisis data dalam penelitian ini menggunakan deskriptif analisis. Metode deskiriptif analisis merupakan metode dengan cara mendeskripsikan faktafakta yang kemudian dianalisis. Secara etimologis deskripsi dan analisis yaitu 
menjabarkan tetapi tidak sekedar menjabarkan melainkan memberikan pengertian serta penjelasan seperlunya (Ratna, 2010:53).

\section{HASIL DAN PEMBAHASAN}

Berdasarkan hasil analisis yang dilakukan peneliti terhadap kumpulan puisi Dongeng-Dongeng yang tak Utuh karya Boy Candra terdapat enam citraan yaitu citraan penglihatan 58 data, pendengaran 21 data, penciuman 4 data, rasaan 5 data, rabaan 27 data, dan gerak 10 data.

\section{A. Citraan dalam kumpulan puisi Dongeng-Dongeng yang tak Utuh}

\section{Citraan penglihatan}

Citraan penglihatan ialah citraan yang ditimbulkan akibat indra penglihatan. Berdasarkan hasil analisis citraan penglihatan merupakan citraan yang banyak dimanfaatkan oleh penyair dalam penulisan puisi Dongeng-Dongeng yang tak Utuh. Berikut ini merupakan kutipan yang mengandung citraan penglihatan yang ditemukan dalam kumpulan puisi Dongeng-Dongeng yang tak Utuh tersebut.

\section{Data (14) \\ anak-anak di ujung desa kurus kering \\ (Boy Candra, Hanya Malam yang Kita Miliki:40)}

Kutipan di atas merupakan citraan penglihatan yang dapat dilihat pada bait ketiga baris ketiga, yaitu /anak-anak di ujung desa kurus kering/. Penggalan puisi di atas menceritakan tentang kekurangan makanan di suatu desa. Pada baris tersebut penyair memberikan rangsangan terhadap indra penglihatan pembaca, sehingga diperoleh gambaran seakan-akan dapat melihat anak-anak kurus seperti kekurangan gizi di ujung desa.

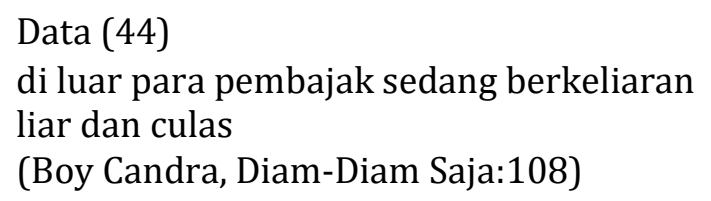

Kutipan di atas merupakan citraan penglihatan yang terdapat dalam bait ke empat baris kedua, yaitu pada baris kedua yang berbunyi /di luar para pembajak sedang berkeliaran/. Melalui baris dalam puisi tersebut daya bayang pembaca terpancing, sehingga diperoleh gambaran bahwa sekan-akan dari suatu ruangan terlihat orang-orang sedang melakukan pembajakan mereka sangat liar dan culas.

\section{Citraan pendengaran}

Citraan pendengaran ialah citraan yang berkaitan dengan pendengaran. Berikut ialah kutipan yang mengandung citraan 
pendengaran yang ditemukan dalam kumpulan puisi Dongeng-Dongeng yang tak Utuh tersebut.

Data (59)

aku rindu bunyi durian jatuh

seperti dentuman bom mungil

(Boy Candra, Bahan Baku Membuat kota:84)

Kutipan di atas adalah citraan pendengaran terdapat pada bait kedua baris kedua, ialah baris yang berbunyi /seperti dentuman bom mungil/. Penyair memberikan gambaran tentang bunyi durian jatuh seperti dentuman bom kecil, baris tersebut memberi rangsangan pada indra pendengaran pembaca. Kata dentuman memperjelas bahwa penggalan puisi tersebut menggunakan citraan pendengaran dimana dentuman memiliki arti bunyi dentum yaitu tiruan bunyi yang berat dan keras.

\section{Data (77)}

isak tangis anak kecil di belakang tungku

(Boy Candra, Suara yang Tak Memihak pada Tanah:138)

Kutipan di atas merupakan citraan pendengaran terdapat pada bait kesatu baris kedua, ialah pada baris yang berbunyi /isak tangis anak kecil di belakang tungku/. Melalui baris tersebut Boy Candra memberikan rangsangan terhadap indra pendengaran pembaca, sehingga diperoleh gambaran seolah-olah dapat mendengaran suara tangisan anak kecil yang berada di belakang tungku.

\section{Citraan penciuman}

Cintraan penciuman ialah ciraan yang berkaitan dengan indra penciuman. Citraan penciuman merupakan citraan yang jarang dimanfaatkan atau di temukan dalam puisi Dongeng-Dongeng yang tak Utuh. Berikut ini merupakan kutipan yang mengandung citraan penciuman yang ditemukan dalam puisi Dongeng-Doneng yang tak utuh.

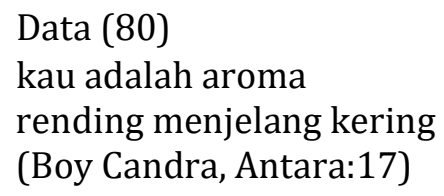

Kutipan di atas adalah citraan penciuman terdapat pada bait kedua baris kesatu, ialah pada baris yang berbunyi /kau adalah aroma/. Penyair mendorong imajinasi pembaca untuk merasakan apa yang ditulisnya, sehingga pada baris tersebut diperoleh gambaran seakan- 
akan dapat mencium aroma rendang yang sudah kering yang di perjelas pada baris kedua. Aroma mempunyai arti bau-bauan yang harum.

Data (83)

di ikan-ikan laut yang asin dan amis

(Boy Candra, Mencari Diri Sendiri:130)

Kutipan di atas ialah citraan penciuman terlihat pada bait kedua baris ketiga, yaitu pada baris yang berbunyi /di ikan-ikan laut yang asin dan amis/. Boy Candra memberikan dorongan pada indra penciuman pembaca untuk dapat mersakan apa yang ditulisnya, sehingga dalam baris tersebut diperoleh gambaran seakan-akan dapat mencium bau amis dari ikan-ikan laut. Kata amis memperjelas bahwa puisi tersebut menggunakan citraan penciuman dimana amis mempunyai arti anyir.

\section{Citraan rasaan}

Citraan rasaan ialah citraan yang ditimblkan akibat indra pencecapan. Berikut merupakan kutipan yang mengandung citraan rasaan yang ditemukan dalam puisi Dongeng-Dongeng yang tak Utuh.

\section{Data (85)}

makan beras dan air asin direbus secara miskin

(Boy Candra, Hanya Malam yang Kita Miliki:40)

Kutipan di atas adalah citraan rasaan dapat dilihat pada bait ketiga baris keempat, yaitu pada baris yang berbunyi /makan beras dan air asin direbus secara miskin/, lewat baris tersebut daya bayang pembaca terpancing sehingga diperoleh gambaran bahwa seakan-akan merasakan air yang asin.

\section{Data (87) \\ udara pahit serupa kehidupan \\ (Boy Candra, Babak Kehidupan:142)}

Kutipan di atas merupakan citraan rasaan terdapat pada bait keenam baris kedua, ialah /udara pahit serupa kehidupan/. Penyair mendorong daya bayang pembaca melalui puisi. Dalam baris tersebut penyair memberikan gambaran bahwa udara pahit seperti kehidupan yang begitu sulit. Kata pahit memperjelas bahwa puisi tersebut menggunakan citraan rasaan dimana pahit mempunyai arti rasa tidak sedap seperti empedu. 


\title{
5. Citraan rabaan
}

Citraan rabaan ialah citraan yang ditimbulkan akibat indra kulitnya. Berikut ini merupakan kutipan yang mengandung citraan rabaan yang ditemukan dalam puisi Dongeng-Dongeng yang tak Utuh.

Data (104)

biarlah dadaku disayat empedu diiris

(Boy Candra, Untuk Cinta Yang Sedih:73)

Kutipan di atas merupakan citraan rabaan dapat dilihat pada bait kedua baris ketiga, ialah baris yang berbunyi /biarlah dadaku disayat empedu diiris/. Citraan rabaan dimanfaatkan Boy Candra untuk mengambarkan suasana sendu dalam puisi. Dalam baris tersebut diperoleh gambaran bahwa seakan-akan dapat merasakan betapa sakitnya ketika dada tersayat dan hati diiris.

Data (113)

hingga kulitmu terbakar matahari, kau tidak pernah peduli

(Boy Candra, Sajak Untuk Nenek:126)

Kutipan di atas adalah citraan rabaan terdapat pada bait keempat baris kelima, ialah baris yang berbunyi /hingga kulitmu terbakar matahari/. Penyair memberikan rangsangan terhadap indra rabaan pembaca, sehingga diperoleh gambaran bahwa seolah-olah merasakan kulit terbakar oleh teriknya matahari.

\section{Citraan gerak}

Citraan gerak yaitu menggambarkan sesuatu yang diam seakanakan dapat bergerak. Berikut merupakan kutipan yang mengandung citraan gerak yang ditemukan dalam puisi Dongeng-Dongeng yang tak Utuh.

\author{
Data (124) \\ pahami gejala riak gelombang \\ (Boy Candra, Diam-Diam Saja:108)
}

Kutipan di atas merupakan citraan gerak yang ditemukan pada bait ketiga baris kempat, ialah /pahami gejala riak gelombang/. Dalam baris tersebut daya bayang pembaca terpancing, sehingga diperoleh gambaran bahwa seakan-akan merasakan gerakan ombak di atas permukaan air. Kata riak memilik arti gerakan.

Data (125)

bumbu-bumbu mengalir di darah

(Boy Candra, Nasi Padang:112) 
Kutipan di atas merupakan citraan gerak yang terdapat pada bait kesatu baris ketiga, yakni yang berbunyi /bumbu-bumbu mengalir di darah/. Pada penggalan puisi tersebut penyair merangsang daya bayang pembaca, sehingga seolah-olah dapat merasakan apa yang tiulisnya. Dalam baris di atas penyair menggambarkan seakan-akan bumbubumbu dapat mengalir di darah. Kata mengalir memiliki arti bergerak maju.

\section{B. Implikasi Hasil Penelitian terhadap Pembelajaran Bahasa Indonesia di SMP}

Penelitian mengenai citraan dalam kumpulan puisi Dongeng-Dongeng yang tak Utuh karya Boy Candra diimplikasikan pada pembelajaran bahasa Indonesia tingkat Sekolah Menengah Pertama (SMP) kelas VIII pada KD 3.7 yaitu mengidentifikasi unsur-unsur pembangun teks puisi yang diperdengarkan atau dibaca dan KD 4.7 yaitu menyimpulkan unsur-unsur pembangun dan makna teks puisi yang diperdengarkan atau dibaca. Aspek keterampilan berbahasa dan sastra meliputi: menyimak, berbicara, membaca, dan menulis. Siswa diharapkan mampu mencapai tujuan pembelajaran yang sesuai dengan kompetensi dasar dengan aspek keterampilan tersebut.

\section{PENUTUP}

Simpulan

Terdapat enam jenis citraan yang digunakan dalam kumpulan Puisi DongengDoneng yang tak Utuh ialah citraan penglihatan, citraan pendengaran, citraan penciuman, citraan rasaan, citraan rabaan, dan citraan gerak. Citraan yang banyak digunakan yaitu citraan penglihatan sedangkan citraan yang jarang digunakan ialah citraan penciuman. Hampir disetiap puisi Dongeng-Dongeng yang tak Utuh terdapat citraan.

Hasil penelitian ini akan diimplikasikan pada pembelajaran sastra tingkat Sekolah Menengah Pertama (SMP) kelas VIII pada KD 3.7 yaitu mengidentifikasi unsur-unsur pembangun teks puisi yang diperdengarkan atau dibaca dan KD 4.7 yaitu menyimpulkan unsur-unsur pembangun dan makna teks puisi yang diperdengarkan atau dibaca.

\section{Saran}

Dari hasil analisis citraan dalam kumpulan puisi Dongeng-Dongeng yang tak Utuh disarankan bahwa hasil dari penelitian ini hendaknya dapat menambah pengetahuan tentang karya sastra khususnya puisi. Penelitian ini hendaknya dapat menjadi pedoman bagi guru dan calon guru, serta mahasiswa dalam menganalisi citraan dalam puisi. Penelitian ini dapat dijadikan sebagai bahan perbandingan untuk melakukan penelitian sejenis mengenai citraan dalam kumpulan puisi tetapi dengan menggunakan objek yang berbeda sehingga dapat menghasilkan data yang maksimal dan akurat. 


\section{DAFTAR PUSTAKA}

Candra, Boy. 2019. Dongeng-Dongeng yang tak Utuh. Jakarta: Mediakita.

Hasanuddin WS. 2002. Membaca dan Menilai Sajak. Bandung: Angkasa.

Laila, Arun. 2016. "Citraan dalam Kumpulan Puisi Mengutak di Negeri Prosaliris karya Rusli Marzuki Saria". Jurnal Gramatika STKIP PGRI Sumatra Barat. V2.iI (12-24).

Mabruri, Zuniar Kamaluddin, dan Sri Dwi Ratnasari. 2105. "Majas dan Citraan dalam Kumpulan Puisi Blues untuk Bonnie karya W.S. Rendra dan Pemakaiannya". Culture. Vol.2, No.1, 133-150.

Maulina, Yeni. 2016. "Citraan dalam Kumpulan Sajak Orgasmaya karya Hasan Aspahani”. Madah. Volume 7, Nomor 2, 177-184.

Pradopo, Rachmat Djoko. 2012. Pengkajian Puisi. Yogyakarta: Gadjah Mada University Press.

Rahimah, Anni. 2017. "Citraan dalam Puisi Surat Cinta karya WS. Rendra". Jurnal Education and development STKIP Tapanul Selatan. Vol.4, No.3, 93-98.

Ratna, Nyoman Kutha. 2010. Teori, Metode, dan Teknik Penelitian Sastra. Yogyakarta. Pustaka Pelajar.

Siswantoro. 2010. Metode Penelitian Sastra. Yogyakarta: Pustaka Pelajar.

Sujoko, dan Edy Pranata Nasution. 2020. "Citraan dalam Kumpulan Puisi Syahadat Senggama karya Asro Al Murthawy". Jurnal Ilmiah Pendidikan Bahasa dan Sastra Indonesia. Vol. 4, No. 1, 111-118.

Yono, Robert Rizki, dan Mimi Mulyani. 2017. "Majas dan Citraan dalam Novel Kerling Si Janda karya Taufiqurrahman Al-Azizy". Jurnal Pendidikan Bahasa dan Sastra Indonesia. 6(2), 200-207. 